Annals of Pure and Applied Mathematics

Vol. 15, No. 1, 2017, 133-144

ISSN: 2279-087X (P), 2279-0888(online)

Published on 11 December 2017

www.researchmathsci.org

DOI: http://dx.doi.org/10.22457/apam.v15n1a13

Annals of

Pure and Applied

Mathematics

\title{
Gem-Separation Axioms in Topological Space
}

\author{
R. Rathinam ${ }^{1}$ and C. Elango ${ }^{2}$ \\ ${ }^{1}$ Theni Kammavar Sangam College of Arts and Science \\ Theni, Tamilnadu, India 625534 \\ ${ }^{2}$ Cardamom Planters' Association College, Bodinayakanur \\ Tamilnadu, India 625513 \\ ${ }^{1}$ Corresponding author
}

Received 2 November 2017; accepted 4 December 2017

\begin{abstract}
In this article we introduce a new separation axioms to define Gem-regular space, Gem-normal space, Gem-completely normal space, Gem-perfectly normal space and $G^{*}-T_{i}$-spaces for $\mathrm{i}=3,4,5$ and 6 under the idea of "Gem-set" and study some of its basic properties and relations among them.
\end{abstract}

Keywords: Gem-set, Gem-regular space, Gem-normal space Gem-completely normal space and Gem-perfectly normal space, and $G^{*}-T_{i}$-spaces.

AMS Mathematics Subject Classification (2010): 46M20

\section{Introduction}

The concept of ideals in topological spaces are treated in the standard text by Kuratowski [8] and Vaidyanathaswamy [16]. In 'general topology' Hamlett and Jankovic [2, 3, 4, 17, 18] introduced the application of topological ideal as defined below : An ideal $\mathcal{J}$ on a topological space ( $\mathrm{X}, \tau$ ) is a non empty collection of subsets of $\mathrm{X}$ having the following properties : (i) $\mathrm{A} \in \mathcal{J}$ and $\mathrm{B} \subseteq \mathrm{A}$ implies $\mathrm{B} \in \mathcal{J}$. (ii) $\mathrm{A} \in \mathcal{J}$ and $\mathrm{B} \in \mathcal{J}$ implies $\mathrm{A} \cup \mathrm{B} \in \mathcal{J}$. An ideal topological space is a toplogical space $(X, \tau)$ with an ideal $\mathcal{J}$ on $X$ and is denoted by $(\mathrm{X}, \tau, \mathcal{J})$. In addition $\mathrm{K}$. Kuratowski[8] defined the local function for $\mathrm{A} \subseteq \mathrm{X}$ with respect to $\mathcal{J}$ and $\tau$ as below : $A^{*}(\mathcal{J}, \tau)$ or $A^{*}(\mathcal{J})=\{\mathrm{x} \in \mathrm{X}: \mathrm{A} \cap \mathrm{U} \notin \mathcal{J}$ for any $\mathrm{U} \in$ $\tau(\mathrm{x})\}$ where $\tau(\mathrm{x})=\{\mathrm{U} \in \tau: \mathrm{x} \in \mathrm{U}\}$. We simply write $A^{*}$ instead of $A^{*}(\mathcal{J})$. Arenas, Dontchev and Puertas [5] introduced some weak separation axioms under the concept of ideal. Swidi and Sada[10] introduced a new type of ideal for a single point $x$ denoted as $J_{x}$ and is defined as below : $\mathcal{J}_{x}=\left\{\mathrm{U} \subseteq \mathrm{X}: \mathrm{x} \in U^{c}\right\}$, where $\mathrm{U}$ is a non-empty subset of $X$. Swidi and Nafee [9] introduced a new set in topological space namely "Gem-set" depending on the $J_{x}$ and defined a new separation axioms by using the idea of the "Gemset" namely $I^{*}-T_{i}$-spaces and $I^{* *}-T_{i}$-spaces for $\mathrm{i}=0,1$ and 2 . They also defined two mappings namely "I*-map" and " $I^{* *}$-map" to carry properties of the "Gem-set" from one space to another space and give more properties for new separation axioms. Swidi and Ethary [12] introduced a new class of maps namely "A-map", "AO-map" and "Am-map" under the idea of the Gem-set and studied some of its basic properties and relations as well as the properties of the separation axioms of $I^{*}-T_{i}$-spaces and $I^{* *}-T_{i}$-spaces for $\mathrm{i}=0$, 1 and 2 with the functions and their effect upon them are also establised. 


\section{R. Rathinam and C. Elango}

Aim of this article is to introduce the separation axioms to define Gem-regular space $\left(\mathrm{G}-T_{3}\right)$, Gem-normal space $\left(\mathrm{G}-T_{4}\right)$, Gem-compleletely normal space $\left(\mathrm{G}-T_{5}\right)$, Gemperfectly normal space $\left(\mathrm{G}-T_{6}\right)$ and $G^{*}-T_{i}$-spaces for $\mathrm{i}=3,4,5$ and 6 and study some of its basic properties. Also we study the relations as well as the properties of G-T $T_{i}$-spaces and $G^{*}-T_{i}$-spaces for $\mathrm{i}=3,4,5$ and 6 in connection with the functions " $I^{*}$-map", "I**-map" "A-map" and "AO-map" and the effect upon them.

Throughout this paper, spaces means topological spaces on which no separation axioms are assumed unless otherwise mentioned.

\section{Preliminaries}

Definition 2.1. Let ( $\mathrm{X}, \tau$ ) be a topological space, for $\mathrm{A} \subseteq \mathrm{X}$ and $\mathrm{x} \in \mathrm{X}$ we define $A^{* x}$ with respect to $(\mathrm{X}, \tau)$ as follows :

$A^{* x}=\left\{\mathrm{y} \in \mathrm{X}: \mathrm{G} \cap \mathrm{A} \notin \mathcal{J}_{x}\right.$, for every $\left.\mathrm{G} \in \tau(\mathrm{y})\right\}$, where $\tau(\mathrm{y})=\{\mathrm{G} \in \tau: \mathrm{y} \in \mathrm{G}\}$. The set $A^{* x}$ is called "Gem-set".

Definition 2.2. Consider the mapping $\mathrm{f}:(\mathrm{X}, \tau) \rightarrow(\mathrm{Y}, \sigma)$, then $\mathrm{f}$ is called

- $\quad I^{*}$-map if and only if, for every subset A of X, $\mathrm{x} \in \mathrm{X}, f\left(A^{* x}\right)=(f(A))^{* f(x)}$.

- $I^{* *}$-map if and only if, for every subset $\mathrm{A}$ of $\mathrm{Y}, \mathrm{y} \in \mathrm{Y}$, $f^{-1}\left(A^{* y}\right)=\left(f^{-1}(A)\right)^{* f^{-1}(y)}$.

Definition 2.3. Consider the mapping $\mathrm{f}:(\mathrm{X}, \tau) \rightarrow(\mathrm{Y}, \sigma)$, then $\mathrm{f}$ is an

- $\quad$ A-map at $\mathrm{x} \in \mathrm{X}$, if and only if $\forall \mathrm{B} \subseteq \mathrm{Y}, \exists \mathrm{A} \subseteq \mathrm{X} \ni: f\left(A^{* x}\right) \subseteq B^{* f(x)}$.

- A-map on $X$ if and only if it is an A-map at each point on $X$.

- $\mathrm{AO}$-map if and only if $\forall \mathrm{A} \subseteq \mathrm{X}, \exists \mathrm{B} \subseteq \mathrm{Y} \ni: B^{* y} \subseteq f\left(A^{* f^{-1(y)}}\right)$.

\section{Gem-separation axioms}

In this section we define Gem-regular space, Gem-normal space, Gem-completely normal space, Gem-perfectly normal space and $G^{*}-T_{i}$-spaces for $\mathrm{i}=3,4,5$ and 6 and derive some of its basic properties.

Definition 3.1. A topological space $(\mathrm{X}, \tau)$ is a

- $\quad$ Gem-regular space or $\mathrm{G}-T_{3}$-space if and only if for each disjoint pair consisting a point $\mathrm{x}$ and a set $\mathrm{C}$ in $\mathrm{X}$, there exists subsets $\mathrm{A}, \mathrm{B}$ of $\mathrm{X}$ such that $\mathrm{x} \notin B^{* y}$ and $\mathrm{C} \nsubseteq A^{* x}$.

- Gem-normal space or G-T $T_{4}$-space if and only if for each pair $\mathrm{C}$ and $\mathrm{D}$ of disjoint sets in $\mathrm{X}$, there exists subsets $\mathrm{A}, \mathrm{B}$ of $\mathrm{X}$ such that $\mathrm{C} \nsubseteq B^{* y}$ and $\mathrm{D} \nsubseteq A^{* x}$.

- $\quad$ Gem-completely normal space or $\mathrm{G}-T_{5}$-space if and only if for each pair of separated sets $\mathrm{C}$ and $\mathrm{D}$ in $\mathrm{X}$, there exists subsets $\mathrm{A}, \mathrm{B}$ of $\mathrm{X}$ such that $\mathrm{C} \nsubseteq B^{* y}$ and $\mathrm{D}$ $\nsubseteq A^{* x}$

- $\quad$ Gem-perfectly normal space or G- $T_{6}$-space if and only if for each pair $\mathrm{C}$ and D of disjoint sets in $\mathrm{X}$, there exists a continuous map $\mathrm{f}: \mathrm{X} \rightarrow[0,1]$ such that $C^{* x} \neq f^{-1}(\{1\})$ and $D^{* y} \neq f^{-1}(\{0\})$.

- $\quad G^{*}-T_{3}$-space if and only if for each disjoint pair consisting a point $\mathrm{x}$ and a set $\mathrm{C}$ in $\mathrm{X}$, there exists subset $\mathrm{A}$ of $\mathrm{X}$ such that $\mathrm{x} \notin A^{* y}$ and $\mathrm{C} \nsubseteq A^{* x}$.

- $\quad G^{*}-T_{4}$-space if and only if for each pair $\mathrm{C}$ and $\mathrm{D}$ of disjoint sets in $\mathrm{X}$, there exists subset $\mathrm{A}$ of $\mathrm{X}$ such that $\mathrm{C} \nsubseteq A^{* y}$ and $\mathrm{D} \nsubseteq A^{* x}$. 


\section{Gem-Separation Axioms in Topological Space}

- $\quad G^{*}-T_{5}$-space if and only if for each pair of separated sets $\mathrm{C}$ and D in X, there exists subset $\mathrm{A}$ of $\mathrm{X}$ such that $\mathrm{C} \nsubseteq A^{* y}$ and $\mathrm{D} \nsubseteq A^{* x}$.

- $\quad G^{*}-T_{6}$-space if and only if for each pair $\mathrm{C}$ and $\mathrm{D}$ of disjoint sets in $\mathrm{X}$, there exists a continuous map $\mathrm{f}: \mathrm{X} \rightarrow[0,1]$ such that $C^{* x} \neq f^{-1}(\{1\})$ and $D^{* y}=f^{-1}(\{1\}) \operatorname{or} C^{* x}=$ $f^{-1}(\{0\})$ and $D^{* y} \neq f^{-1}(\{0\})$

Theorem 3.2. For a topological space $(X, \tau)$ the following properties hold good :

1. Every $T_{3}$-space is a G- $T_{3}$-space.

2. Every $T_{4}$-space is a G-T $T_{4}$-space.

3. Every $T_{5}$-space is a G-T $T_{5}$-space.

4. Every $T_{6}$-space is a G-T $T_{6}$-space.

5. Every $T_{3}$-space is a $G^{*}-T_{3}$-space.

6. Every $T_{4}$-space is a $G^{*}-T_{4}$-space.

7. Every $T_{5}$-space is a $G^{*}-T_{5}$-space.

8. Every $T_{6}$-space is a $G^{*}-T_{6}$-space.

Proof: 1. Let $\mathrm{x} \in \mathrm{X}$ and $\mathrm{C}$ be a closed set in $\mathrm{X}$ with $\mathrm{x} \notin \mathrm{C}$. Since $(X, \tau)$ is a $T_{3}$-space. Then there exists disjoint open sets $\mathrm{U}, \mathrm{V}$ such that $\mathrm{x} \in \mathrm{U}$ and $\mathrm{C} \subseteq \mathrm{V}$. Then $U^{* x} \cap V^{* y}=$ $\phi$. Let $\mathrm{A}=\mathrm{U}, \mathrm{B}=\mathrm{V}$. It follows that there exists subsets $\mathrm{A}, \mathrm{B}$ of $\mathrm{X}$ such that $\mathrm{x} \notin B^{* y}$ and $\mathrm{C} \nsubseteq A^{* x}$. Hence $(\mathrm{X}, \tau)$ is a $\mathrm{G}-T_{3}$-space.

2. Let $\mathrm{C}$ and $\mathrm{D}$ be the disjoint closed sets in $\mathrm{X}$ and $(\mathrm{X}, \tau)$ is a $T_{4}$-space. Then there exists disjoint open sets $\mathrm{U}, \mathrm{V}$ such that $\mathrm{C} \subseteq \mathrm{U}$ and $\mathrm{D} \subseteq \mathrm{V}$. Then $U^{* x} \cap V^{* y}=\phi$. Let $\mathrm{A}=\mathrm{U}, \mathrm{B}$ $=\mathrm{V}$. It follows that there exists subsets $\mathrm{A}, \mathrm{B}$ of $\mathrm{X}$ such that $\mathrm{C} \nsubseteq B^{* y}$ and $\mathrm{D} \nsubseteq A^{* x}$. Hence $(\mathrm{X}, \tau)$ is a $\mathrm{G}-T_{4}$-space.

3. Let $\mathrm{C}$ and $\mathrm{D}$ be the separated sets in $\mathrm{X}$ ( i.e $\bar{C} \cap \mathrm{D}=\mathrm{C} \cap \bar{D}=\phi$ ) and ( $\mathrm{X}, \tau$ ) is a $T_{5^{-}}$ space. Then there exists disjoint open sets $\mathrm{U}, \mathrm{V}$ such that $\mathrm{C} \subseteq \mathrm{U}$ and $\mathrm{D} \subseteq \mathrm{V}$. Then $U^{* x} \cap V^{* y}=h i$. Let $\mathrm{A}=\mathrm{U}, \mathrm{B}=\mathrm{V}$. It follows that there exists subsets $\mathrm{A}, \mathrm{B}$ of $\mathrm{X}$ such that $\mathrm{C} \nsubseteq B^{* y}$ and $\mathrm{D} \Phi A^{* x}$. Hence ( $\left.\mathrm{X}, \tau\right)$ is a $\mathrm{G}-T_{5}$-space.

4. Let $\mathrm{C}$ and $\mathrm{D}$ be the disjoint closed sets in $\mathrm{X}$ and $(\mathrm{X}, \tau)$ is a $T_{6}$-space. Then there exists a continuous map $\mathrm{f}: \mathrm{X} \rightarrow[0,1]$ such that, $\mathrm{C}=f^{-1}(\{0\})$ and $\mathrm{D}=f^{-1}(\{1\})$. Then $C^{* x} \cap D^{* y}=\phi$. It follows that there exists a continuous map $\mathrm{f}: \mathrm{X} \rightarrow[0,1]$ such that $C^{* x} \neq f^{-1}(\{1\})$ and $D^{* y} \neq f^{-1}(\{0\})$. Hence $(\mathrm{X}, \tau)$ is a G-T $T_{6}$-space.

5. Let $\mathrm{x} \in \mathrm{X}$ and $\mathrm{C}$ be a closed set in $\mathrm{X}$ with $\mathrm{x} \notin \mathrm{C}$. Since $(\mathrm{X}, \tau)$ is a $T_{3}$-space. Then there exists disjoint open sets $\mathrm{U}, \mathrm{V}$ such that $\mathrm{x} \in \mathrm{U}$ and $\mathrm{C} \subseteq \mathrm{V}$. Then $U^{* x} \cap V^{* y}=\phi$. Let $\mathrm{U}=\mathrm{V}=\mathrm{A}$. It follows that there exists a subset $\mathrm{A}$ of $\mathrm{X}$ such that $\mathrm{x} \notin A^{* y}$ and $\mathrm{C} \notin A^{* x}$. Hence $(\mathrm{X}, \tau)$ is a $G^{*}-T_{3}$-space.

6. Let $\mathrm{C}$ and $\mathrm{D}$ be the disjoint closed sets in $\mathrm{X}$ and $(\mathrm{X}, \tau)$ is a $T_{4}$-space. Then there exists disjoint open sets $\mathrm{U}, \mathrm{V}$ such that $\mathrm{C} \subseteq \mathrm{U}$ and $\mathrm{D} \subseteq \mathrm{V}$. Then $U^{* x} \cap V^{* y}=\phi$. Let $\mathrm{U}=\mathrm{V}=$ A. It follows that there existssubsets $\mathrm{A}, \mathrm{B}$ of $\mathrm{X}$ such that $\mathrm{C} \nsubseteq A^{* y}$ and $\mathrm{D} \nsubseteq A^{* x}$. Hence ( $\mathrm{X}, \tau)$ is a $G^{*}-T_{4}$-space.

7. Let $\mathrm{C}$ and $\mathrm{D}$ be the separated sets in $\mathrm{X}$ and $(\mathrm{X}, \tau)$ is a $T_{5}$-space. Then there exists disjoint open sets $\mathrm{U}, \mathrm{V}$ such that $\mathrm{C} \subseteq \mathrm{U}$ and $\mathrm{D} \subseteq \mathrm{V}$. Then $U^{* x} \cap V^{* y}=\phi$. Let $\mathrm{U}=\mathrm{A}=$ $\mathrm{V}$. It follows that there exists subsetA of $\mathrm{X}$ such that $\mathrm{C} \nsubseteq A^{* y}$ and $\mathrm{D} \nsubseteq A^{* x}$. Hence ( $\mathrm{X}, \tau$ ) is a $G^{*}-T_{5}$-space.

8. Let $\mathrm{C}$ and $\mathrm{D}$ be the disjoint closed sets in $\mathrm{X}$ and $(\mathrm{X}, \tau)$ is a $T_{6}$-space. Then there exists a continuous map $\mathrm{f}: \mathrm{X} \rightarrow[0,1]$ such that, $\mathrm{C}=f^{-1}(\{0\})$ and $\mathrm{D}=f^{-1}(\{1\})$. Then 


\section{R. Rathinam and C. Elango}

$C^{* x} \cap D^{* y}=\phi$. It follows that there exists a continuous map $\mathrm{f}: \mathrm{X} \rightarrow[0,1]$ such that $C^{* x} \neq f^{-1}(\{1\})$ and $D^{* y}=f^{-1}(\{1\})$ or $C^{* x}=f^{-1}(\{0\})$ and $D^{* y} \neq f^{-1}(\{0\})$ Hence $(\mathrm{X}$, $\tau$ ) is a $G^{*}-T_{6}$-space.

Remark : The converse of the above theorem need not be true.

\subsection{G-T $T_{3}$-space}

In this section we proved some theorems in connection with $I^{*}$-map, $I^{* *}$-map, A-map and AO-map for $\mathrm{G}-\mathrm{T}_{3}$-space.

Theorem 3.1.1. If $\mathrm{f}:(\mathrm{X}, \tau) \rightarrow(\mathrm{Y}, \sigma)$ is one-one $I^{*}$-map of a $\mathrm{G}$ - $T_{3}$-space $\mathrm{X}$ onto a space $\mathrm{Y}$, then $\mathrm{Y}$ is a $\mathrm{G}-T_{3}$-space.

Proof: Let $y_{1}$ and $C_{2}$ be a disjoint pair of $Y$. Since $f$ is one-one and onto, there exists disjoint pair $x_{1}$ and $C_{1}$ of $\mathrm{X}$ such that $f\left(x_{1}\right)=y_{1}$ and $\mathrm{f}\left(C_{1}\right)=C_{2}$. Since $(\mathrm{X}, \tau)$ is G- $T_{3}$ space, there exists subsets $\mathrm{A}$ and $\mathrm{B}$ of $\mathrm{X}$ such that $x_{1} \notin B^{* x_{2}}$ and $C_{1} \nsubseteq A^{* x_{1}}$, so that $f\left(x_{1}\right) \notin f\left(B^{* x_{2}}\right)=(f(B))^{* f\left(x_{2}\right)} \quad$ and $\quad f\left(C_{1}\right) \nsubseteq f\left(A^{* x_{1}}\right)=(f(A))^{* f\left(x_{1}\right)}$. Thus $y_{1} \notin(f(B))^{* f\left(x_{2}\right)=y_{2}}$ and $C_{2}$ bseteq $(f(A))^{* f\left(x_{1}\right)=y_{1}}$. Thus $\mathrm{Y}$ is a G-T $T_{3}$-space.

Theorem 3.1.2. If $\mathrm{f}:(\mathrm{X}, \tau) \rightarrow(\mathrm{Y}, \sigma)$ is one-one $I^{* *}$-map of a space $\mathrm{X}$ onto $\mathrm{G}-T_{3}$-space $\mathrm{Y}$, then $\mathrm{X}$ is a $\mathrm{G}-T_{3}$-space.

Proof: Let $x_{1}$ and $C_{1}$ be a disjoint pairs of $\mathrm{X}$. Since $\mathrm{f}$ is one-one and onto, there exists disjoint pairs $y_{1}$ and $C_{2}$ of Y such that $f\left(x_{1}\right)=y_{1}$ and $f\left(C_{1}\right)=C_{2}$. Since $(\mathrm{Y}, \sigma)$ is G- $T_{3}$ space, there exists subsets $\mathrm{A}, \mathrm{B}$ of $\mathrm{Y}$ such that $y_{1} \notin B^{* y_{2}}$ and $C_{2} \nsubseteq A^{* y_{1}}$, so that $f^{-1}\left(y_{1}\right) \notin f^{-1}\left(B^{* y_{2}}\right)=\left(f^{-1}(B)\right)^{* f^{-1}\left(\left(y_{2}\right)\right)} \quad$ and $\quad f^{-1}\left(C_{2}\right) \nsubseteq f^{-1}\left(A^{* y_{1}}\right) \quad=$ $\left(f^{-1}(A)\right)^{* f^{-1}\left(y_{1}\right)}$. This implies $x_{1} \notin\left(f^{-1}(B)\right)^{* x_{2}}$ and $C_{1} \nsubseteq\left(f^{-1}(A)\right)^{* x_{1}}$. Thus $\mathrm{X}$ is a G$T_{3}$-space.

Theorem 3.1.3. If $\mathrm{f}:(\mathrm{X}, \tau) \rightarrow(\mathrm{Y}, \sigma)$ is one-one A-map of a $\mathrm{G}-T_{3}$-space $\mathrm{X}$ onto a space $Y$, then $Y$ is a $G-T_{3}$-space.

Proof: Let $y_{1}$ and $C_{2}$ be a disjoint pair of $\mathrm{Y}$. Since $\mathrm{f}$ is one-one and onto, there exists a disjoint pair $x_{1}$ and $C_{1}$ of X such that $f\left(x_{1}\right)=y_{1}$ and $f\left(C_{1}\right)=C_{2}$. Since $(\mathrm{X}, \tau)$ is G- $T_{3^{-}}$ space, there exists subsets $A_{1}, A_{2}$ of $\mathrm{X}$ such that $x_{1} \notin A_{2}^{* x_{2}}$ and $C_{1} \nsubseteq A_{1}^{* x_{1}}$, so that $f\left(x_{1}\right) \notin f\left(A_{2}^{* x_{2}}\right) \subseteq B_{2}^{* f\left(x_{2}\right)}$ and $f\left(C_{1}\right) \nsubseteq f\left(A_{1}^{* x_{1}}\right) \subseteq B_{1}^{* f\left(x_{1}\right)}$. This implies $y_{1} \notin B_{2}^{* y_{2}}$ and $C_{2} \nsubseteq B_{1}^{* y_{1}}$. Thus $\mathrm{Y}$ is a $\mathrm{G}-T_{3}$-space.

Theorem 3.1.4. If $\mathrm{f}:(\mathrm{X}, \tau) \rightarrow(\mathrm{Y}, \sigma)$ is one-one AO-map of a space $\mathrm{X}$ onto $\mathrm{G}-\mathrm{T}_{3^{-}}$ space $\mathrm{Y}$, then $\mathrm{X}$ is a $\mathrm{G}-T_{3}$-space.

Proof: Let $x_{1}$ and $C_{1}$ be a disjoint pair of $\mathrm{X}$. Since $\mathrm{f}$ is one-one and onto, there exists a disjoint pair $y_{1}$ and $C_{2}$ of Y such that $f\left(x_{1}\right)=y_{1}$ and $f\left(C_{1}\right)=C_{2}$. Since $(\mathrm{Y}, \sigma)$ is G- $T_{3}$ space, there exists subsets $B_{1}, B_{2}$ of $\mathrm{Y}$ such that $y_{1} \notin B_{2}^{* y_{2}} \subseteq f\left(A_{2}^{* f^{-1}\left(y_{2}\right)}\right)$ and $C_{2} \nsubseteq B_{1}^{* y_{1}} \subseteq f\left(A_{1}^{* f^{-1}\left(y_{1}\right)}\right)$, so that $f^{-1}\left(y_{1}\right) \notin f^{-1}\left(f\left(A_{2}^{* f^{-1}\left(y_{2}\right)}\right)\right) \quad$ and $f^{-1}\left(C_{2}\right) \not f^{-1}\left(f\left(A_{1}^{* f^{-1}\left(y_{1}\right)}\right)\right)$. This implies $x_{1} \notin A_{2}^{* x_{2}}$ and $C_{1} \nsubseteq A_{1}^{* x_{1}}$. Thus $\mathrm{X}$ is a G-T $3^{-}$ space. 
Gem-Separation Axioms in Topological Space

\subsection{G-T $T_{4}$-space}

In this section we proved some theorems in connection with $I^{*}$-map, $I^{* *}$-map, A-map and AO-map for $\mathrm{G}-T_{4}$-space.

Theorem 3.2.1. If $\mathrm{f}:(\mathrm{X}, \tau) \rightarrow(\mathrm{Y}, \sigma)$ is one-one $I^{*}$-map of a $\mathrm{G}-T_{4}$-space $\mathrm{X}$ onto a space $\mathrm{Y}$, then $\mathrm{Y}$ is a $\mathrm{G}-\mathrm{T}_{4}$-space.

Proof: Let $C_{2}$ and $D_{2}$ be two disjoint sets in Y. Since $\mathrm{f}$ is one-one and onto, there exists disjoint sets $C_{1}$ and $D_{1}$ of $\mathrm{X}$ such that $f\left(C_{1}\right)=C_{2}$ and $\mathrm{f}\left(D_{1}\right)=D_{2}$. Since $(\mathrm{X}, \tau)$ is G-T $T_{4}$ space, there exists subsets $\mathrm{A}$ and $\mathrm{B}$ of $\mathrm{X}$ such that $C_{1} \nsubseteq B^{* x_{2}}$ and $D_{1} \nsubseteq A^{* x_{1}}$, so that $f\left(C_{1}\right) \nsubseteq f\left(B^{* x_{2}}\right)=(f(B))^{* f\left(x_{2}\right)}$ and $f\left(D_{1}\right) \nsubseteq f\left(A^{* x_{1}}\right)=(f(A))^{* f\left(x_{1}\right)}$.

Thus $C_{2} \nsubseteq(f(B))^{* f\left(x_{2}\right)=y_{2}}$ and $D_{2} \nsubseteq(f(A))^{* f\left(x_{1}\right)=y_{1}}$. Thus Y is a G-T $T_{4}$-space.

Theorem 3.2.2. If $\mathrm{f}:(\mathrm{X}, \tau) \rightarrow(\mathrm{Y}, \sigma)$ is one-one $I^{* *}$-map of a space $\mathrm{X}$ onto $\mathrm{G}-T_{4}$-space $\mathrm{Y}$, then $\mathrm{X}$ is a $\mathrm{G}-\mathrm{T}_{4}$-space.

Proof: Let $C_{1}$ and $D_{1}$ be two disjoint sets in X. Since $\mathrm{f}$ is one-one and onto, there exists disjoint sets $C_{2}$ and $D_{2}$ of Y such that $f\left(C_{1}\right)=C_{2}$ and $f\left(D_{1}\right)=D_{2}$. Since ( Y, $\left.\sigma\right)$ is G- $T_{4}$ space, there exists subsets $\mathrm{A}, \mathrm{B}$ of $\mathrm{Y}$ such that $C_{2} \nsubseteq B^{* y_{2}}$ and $D_{2} \nsubseteq A^{* y_{1}}$, so that

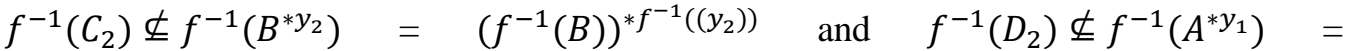
$\left(f^{-1}(A)\right)^{* f^{-1}\left(y_{1}\right)}$. This implies $C_{1} \nsubseteq\left(f^{-1}(B)\right)^{* x_{2}}$ and $D_{1} \nsubseteq\left(f^{-1}(A)\right)^{* x_{1}}$. Thus $\mathrm{X}$ is a G$T_{4}$-space.

Theorem 3.2.3. If $\mathrm{f}:(\mathrm{X}, \tau) \rightarrow(\mathrm{Y}, \sigma)$ is one-one A-map of a $I^{*}-T_{4}$-space $\mathrm{X}$ onto a space $\mathrm{Y}$, then $\mathrm{Y}$ is a $\mathrm{G}-\mathrm{T}_{4}$-space.

Proof: Let $C_{2}$ and $D_{2}$ be two disjoint sets in Y. Since $\mathrm{f}$ is one-one and onto, there exists a disjoint sets $C_{1}$ and $D_{1}$ of $\mathrm{X}$ such that $f\left(C_{1}\right)=C_{2}$ and $f\left(D_{1}\right)=D_{2}$. Since (X, $\tau$ ) is G- $T_{4}$ space, there exists subsets $A_{1}, A_{2}$ of $\mathrm{X}$ such that $C_{1} \nsubseteq A_{2}^{* x_{2}}$ and $D_{1} \nsubseteq A_{1}^{* x_{1}}$, so that $f\left(C_{1}\right) \nsubseteq f\left(A_{2}^{* x_{2}}\right) \subseteq B_{2}^{* f\left(x_{2}\right)}$ and $f\left(D_{1}\right) \nsubseteq f\left(A_{1}^{* x_{1}}\right) \subseteq B_{1}^{* f\left(x_{1}\right)}$. This implies $C_{2} \nsubseteq B_{2}^{* y_{2}}$ and $D_{2} \nsubseteq B_{1}^{* y_{1}}$. Thus $\mathrm{Y}$ is a G-T $T_{4}$-space.

Theorem 3.2.4. If $\mathrm{f}:(\mathrm{X}, \tau) \rightarrow(\mathrm{Y}, \sigma)$ is one-one AO-map of a space $\mathrm{X}$ onto $\mathrm{G}-T_{4}$ space $\mathrm{Y}$, then $\mathrm{X}$ is a $\mathrm{G}-\mathrm{T}_{4}$-space.

Proof: Let $C_{1}$ and $D_{1}$ be two disjoint sets in $\mathrm{X}$. Since $\mathrm{f}$ is one-one and onto, there exists a disjoint sets $C_{2}$ and $D_{2}$ of Y such that $f\left(C_{1}\right)=C_{2}$ and $f\left(D_{1}\right)=D_{2}$. Since (Y, $\left.\sigma\right)$ is G- $T_{4}$ space, there exists subsets $B_{1}, B_{2}$ of $\mathrm{Y}$ such that $C_{2} \nsubseteq B_{2}^{* y_{2}} \subseteq f\left(A_{2}^{* f^{-1}\left(y_{2}\right)}\right)$ and $D_{2} \nsubseteq B_{1}^{* y_{1}} \subseteq f\left(A_{1}^{* f^{-1}\left(y_{1}\right)}\right)$, so that $\quad f^{-1}\left(C_{2}\right) \nsubseteq f^{-1}\left(f\left(A_{2}^{* f^{-1}\left(y_{2}\right)}\right)\right) \quad$ and $f^{-1}\left(D_{2}\right) \nsubseteq f^{-1}\left(f\left(A_{1}^{* f^{-1}\left(y_{1}\right)}\right)\right)$. This implies $C_{1} \nsubseteq A_{2}^{* x_{2}}$ and $D_{1} \nsubseteq A_{1}^{* x_{1}}$. Thus X is a G-T $T^{-}$ space.

\section{3. $\mathrm{G}-T_{5}$-space}

In this section we proved some theorems in connection with $I^{*}$-map, $I^{* *}$-map, A-map and AO-map for G- $T_{5}$-space. 
R. Rathinam and C. Elango

Theorem 3.3.1. If $\mathrm{f}:(\mathrm{X}, \tau) \rightarrow(\mathrm{Y}, \sigma)$ is one-one $I^{*}$-map of a $\mathrm{G}-T_{5}$-space $\mathrm{X}$ onto a space $\mathrm{Y}$, then $\mathrm{Y}$ is a $\mathrm{G}-T_{5}$-space.

Proof: Let $C_{2}$ and $D_{2}$ be separated sets in Y. Since $\mathrm{f}$ is one-one and onto, there exists separated sets $C_{1}$ and $D_{1}$ of X such that $f\left(C_{1}\right)=C_{2}$ and $\mathrm{f}\left(D_{1}\right)=D_{2}$. Since $(\mathrm{X}, \tau)$ is G-T $T_{5^{-}}$ space, there exists subsets $\mathrm{A}$ and $\mathrm{B}$ of $\mathrm{X}$ such that $C_{1} \nsubseteq B^{* x_{2}}$ and $D_{1} \nsubseteq A^{* x_{1}}$, so that $f\left(C_{1}\right) \nsubseteq f\left(B^{* x_{2}}\right)=(f(B))^{* f\left(x_{2}\right)} \quad$ and $\quad f\left(D_{1}\right) \nsubseteq f\left(A^{* x_{1}}\right)=(f(A))^{* f\left(x_{1}\right)}$. Thus $C_{2} \nsubseteq(f(B))^{* f\left(x_{2}\right)=y_{2}}$ and $D_{2} \nsubseteq(f(A))^{* f\left(x_{1}\right)=y_{1}}$. Thus $\mathrm{Y}$ is a G-T $T_{5}$-space.

Theorem 3.3.2. If $\mathrm{f}:(\mathrm{X}, \tau) \rightarrow(\mathrm{Y}, \sigma)$ is one-one $I^{* *}$-map of a space $\mathrm{X}$ onto $\mathrm{G}-T_{5}$-space $\mathrm{Y}$, then $\mathrm{X}$ is a G-T $T_{5}$-space.

Proof: Let $C_{1}$ and $D_{1}$ be separated sets in $\mathrm{X}$. Since $\mathrm{f}$ is one-one and onto, there exists separated sets $C_{2}$ and $D_{2}$ of Y such that $f\left(C_{1}\right)=C_{2}$ and $f\left(D_{1}\right)=D_{2}$. Since ( Y, $\sigma$ ) is G$T_{5}$-space, there exists subsets $\mathrm{A}$, B of $\mathrm{Y}$ such that $C_{2} \nsubseteq B^{* y_{2}}$ and $D_{2} \nsubseteq A^{* y_{1}}$, so that $f^{-1}\left(C_{2}\right) \nsubseteq f^{-1}\left(B^{* y_{2}}\right)=\left(f^{-1}(B)\right)^{* f^{-1}\left(\left(y_{2}\right)\right)} \quad$ and $\quad f^{-1}\left(D_{2}\right) \nsubseteq f^{-1}\left(A^{* y_{1}}\right) \quad=$ $\left(f^{-1}(A)\right)^{* f^{-1}\left(y_{1}\right)}$. This implies $C_{1} \nsubseteq\left(f^{-1}(B)\right)^{* x_{2}}$ and $D_{1} \nsubseteq\left(f^{-1}(A)\right)^{* x_{1}}$. Thus $\mathrm{X}$ is a G$T_{5}$-space.

Theorem 3.3.3. If $\mathrm{f}:(\mathrm{X}, \tau) \rightarrow(\mathrm{Y}, \sigma)$ is one-one A-map of an $\mathrm{G}-T_{5}$-space $\mathrm{X}$ onto a space $\mathrm{Y}$, then $\mathrm{Y}$ is a $\mathrm{G}-\mathrm{T}_{5}$-space.

Proof: Let $C_{2}$ and $D_{2}$ be separated sets in Y. Since $\mathrm{f}$ is one-one and onto, there exists separated sets $C_{1}$ and $D_{1}$ of X such that $f\left(C_{1}\right)=C_{2}$ and $f\left(D_{1}\right)=D_{2}$. Since $(\mathrm{X}, \tau)$ is G$T_{5}$-space, there exists subsets $A_{1}, A_{2}$ of $\mathrm{X}$ such that $C_{1} \nsubseteq A_{2}^{* x_{2}}$ and $D_{1} \nsubseteq A_{1}^{* x_{1}}$, so that $f\left(C_{1}\right) \nsubseteq f\left(A_{2}^{* x_{2}}\right) \subseteq B_{2}^{* f\left(x_{2}\right)}$ and $f\left(D_{1}\right) \nsubseteq f\left(A_{1}^{* x_{1}}\right) \subseteq B_{1}^{* f\left(x_{1}\right)}$. This implies $C_{2} \nsubseteq B_{2}^{* y_{2}}$ and $D_{2} \nsubseteq B_{1}^{* y_{1}}$. Thus $\mathrm{Y}$ is a $\mathrm{G}-T_{5}$-space.

Theorem 3.3.4. If $\mathrm{f}:(\mathrm{X}, \tau) \rightarrow(\mathrm{Y}, \sigma)$ is one-one AO-map of a space $\mathrm{X}$ onto $\mathrm{G}-T_{5^{-}}$ space $\mathrm{Y}$, then $\mathrm{X}$ is a $\mathrm{G}-T_{5}$-space.

Proof: Let $C_{1}$ and $D_{1}$ be separated sets in $\mathrm{X}$. Since $\mathrm{f}$ is one-one and onto, there exists separated sets $C_{2}$ and $D_{2}$ of Y such that $f\left(C_{1}\right)=C_{2}$ and $f\left(D_{1}\right)=D_{2}$. Since ( $\left.\mathrm{Y}, \sigma\right)$ is G$T_{5}$-space, there exists subsets $B_{1}, B_{2}$ of $\mathrm{Y}$ such that $C_{2} \nsubseteq B_{2}^{* y_{2}} \subseteq f\left(A_{2}^{* f^{-1}\left(y_{2}\right)}\right)$ and $D_{2} \nsubseteq B_{1}^{* y_{1}} \subseteq f\left(A_{1}^{* f^{-1}\left(y_{1}\right)}\right)$, so that $f^{-1}\left(C_{2}\right) \nsubseteq f^{-1}\left(f\left(A_{2}^{* f^{-1}\left(y_{2}\right)}\right)\right)$ and $f^{-1}\left(D_{2}\right)$ ot $\subseteq$ $f^{-1}\left(f\left(A_{1}^{* f^{-1}\left(y_{1}\right)}\right)\right)$. This implies $C_{1} \nsubseteq A_{2}^{* x_{2}}$ and $D_{1} \nsubseteq A_{1}^{* x_{1}}$. Thus $\mathrm{X}$ is a G-T $T_{5}$-space.

\subsection{G-T $T_{6}$-space}

In this section we proved some theorems in connection with $I^{*}$-map, $I^{* *}$-map, A-map and AO-map for $\mathrm{G}-\mathrm{T}_{6}$-space.

Theorem 3.4.1. If $\mathrm{f}:(\mathrm{X}, \tau) \rightarrow(\mathrm{Y}, \sigma)$ is one-one $I^{*}$-map of a space $\mathrm{X}$ onto $\mathrm{G}-T_{6}$-space $\mathrm{Y}$, then $\mathrm{X}$ is a $\mathrm{G}-\mathrm{T}_{6}$-space.

Proof: Let $C_{1}$ and $D_{1}$ be two disjoint sets in X. Since $\mathrm{f}$ is one-one and onto, there exists disjoint sets $C_{2}$ and $D_{2}$ of Y such that $f\left(C_{1}\right)=C_{2}$ and $f\left(D_{1}\right)=D_{2}$. Since $\mathrm{f}$ is an $I^{*}$-map, so that $\mathrm{f}\left(C_{1}^{* x_{1}}\right)=\left(f\left(C_{1}\right)\right)^{* f\left(x_{1}\right)}=C_{2}^{* y_{1}}$ and $\mathrm{f}\left(D_{1}^{* x_{2}}\right)=\left(f\left(D_{1}\right)\right)^{* f\left(x_{2}\right)}=D_{2}^{* y_{2}}$ Since $(\mathrm{Y}, \sigma)$ is G- $T_{6}$-space, there exists a continuous map $\mathrm{g}: \mathrm{Y} \rightarrow[0,1]$ such that $C_{2}^{* y_{1}} \neq g^{-1}(\{1\})$ and 
Gem-Separation Axioms in Topological Space

$D_{2}^{* y_{2}} \neq g^{-1}(\{0\})$. This implies $\mathrm{f}\left(C_{1}^{* x_{1}}\right) \neq g^{-1}(\{1\})$ and $\mathrm{f}\left(D_{1}^{* x_{2}}\right) \neq g^{-1}(\{0\})$. Now $\mathrm{g}\left(\mathrm{f}\left(C_{1}^{* x_{1}}\right)\right) \neq(\{1\})$ and $\mathrm{g}\left(\mathrm{f}\left(D_{1}^{* x_{2}}\right)\right) \neq(\{0\})$. This implies $\mathrm{h}\left(C_{1}^{* x_{1}}\right) \neq(\{1\})$ and $\mathrm{h}\left(D_{1}^{* x_{2}}\right) \neq$ (\{0\}). Thus $C_{1}^{* x_{1}} \neq h^{-1}(\{1\})$ and $D_{1}^{* x_{2}} \neq h^{-1}(\{0\})$ where $\mathrm{h}=\mathrm{g} \circ f: \mathrm{X} \rightarrow[0,1]$ is a continuous map. Hence by definition we have $(\mathrm{X}, \tau)$ is a $\mathrm{G}-T_{6}$-space.

Theorem 3.4.2. If $\mathrm{f}:(\mathrm{X}, \tau) \rightarrow(\mathrm{Y}, \sigma)$ is one-one $I^{* *}$-map of a space $\mathrm{X}$ onto $\mathrm{G}-T_{6}$-space $\mathrm{Y}$, then $\mathrm{X}$ is a G- $T_{6}$-space.

Proof: Let $C_{1}$ and $D_{1}$ be two disjoint sets in $\mathrm{X}$. Since $\mathrm{f}$ is one-one and onto, there exists disjoint sets $C_{2}$ and $D_{2}$ of $\mathrm{Y}$ such that $f\left(C_{1}\right)=C_{2}$ and $f\left(D_{1}\right)=D_{2}$. Since $(\mathrm{Y}, \sigma)$ is G-T $T_{6^{-}}$ space, there exists a continuous map $\mathrm{g}: \mathrm{Y} \rightarrow[0,1]$ such that $C_{2}^{* y_{1}} \neq g^{-1}(\{1\})$ and $D_{2}^{* y_{2}} \neq g^{-1}(\{0\})$. So that $f^{-1}\left(C_{2}^{* y_{1}}\right) \neq f^{-1}\left(g^{-1}(\{1\})\right)$ and $f^{-1}\left(D_{2}^{* y_{2}}\right) \neq$ $f^{-1}\left(g^{-1}(\{0\})\right)$. This implies $f^{-1}\left(C_{2}^{* y_{1}}\right) \neq h^{-1}(\{1\})$ and $f^{-1}\left(D_{2}^{* y_{2}}\right) \neq h^{-1}(\{0\})$. Since

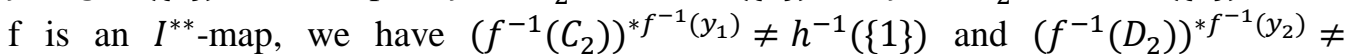
$h^{-1}(\{0\})$. Thus $C_{1}^{* x_{1}} \neq h^{-1}(\{1\})$ and $D_{1}^{* x_{2}} \neq h^{-1}(\{0\})$ where $\mathrm{h}=$ go $f: \mathrm{X} \rightarrow[0,1]$ is a continuous map. Hence by definition we have $(\mathrm{X}, \tau)$ is a $\mathrm{G}-T_{6}$-space.

Theorem 3.4.3. If $\mathrm{f}:(\mathrm{X}, \tau) \rightarrow(\mathrm{Y}, \sigma)$ is one-one A-map of a space $\mathrm{X}$ onto $\mathrm{G}-T_{6}$-space $\mathrm{Y}$, then $\mathrm{X}$ is a $\mathrm{G}-\mathrm{T}_{6}$-space.

Proof: Let $C_{1}$ and $D_{1}$ be two disjoint sets in X. Since $\mathrm{f}$ is one-one and onto, there exists disjoint sets $C_{2}$ and $D_{2}$ of $\mathrm{Y}$ such that $f\left(C_{1}\right)=C_{2}$ and $f\left(D_{1}\right)=D_{2}$. Since $\mathrm{f}$ is an A-map, so that $\mathrm{f}\left(C_{1}^{* x_{1}}\right) \subseteq C_{2}^{* f\left(x_{1}\right)}=C_{2}^{* y_{1}}$ and $\mathrm{f}\left(D_{1}^{* x_{2}}\right) \subseteq D_{2}^{* f\left(x_{2}\right)}=D_{2}^{* y_{2}}$ Since $(\mathrm{Y}, \sigma)$ is G-T - $^{-}$ space, there exists a continuous map g: $\mathrm{Y} \rightarrow[0,1]$ such that $C_{2}^{* y_{1}} \neq g^{-1}(\{1\})$ and $D_{2}^{* y_{2}} \neq g^{-1}(\{0\})$.This implies $\mathrm{f}\left(C_{1}^{* x_{1}}\right) \subseteq C_{2}^{* y_{1}} \neq g^{-1}(\{1\})$ and $\mathrm{f}\left(D_{1}^{* x_{2}}\right) \subseteq D_{2}^{* y_{2}} \neq$ $g^{-1}(\{0\})$. This implies $\mathrm{f}\left(C_{1}^{* x_{1}}\right) \neq g^{-1}(\{1\})$ and $\mathrm{f}\left(D_{1}^{* x_{2}}\right) \neq g^{-1}(\{0\})$. Now $\mathrm{g}\left(\mathrm{f}\left(C_{1}^{* x_{1}}\right)\right) \neq$ $(\{1\})$ and $\mathrm{g}\left(\mathrm{f}\left(D_{1}^{* x_{2}}\right)\right) \neq(\{0\})$. This implies $\mathrm{h}\left(C_{1}^{* x_{1}}\right) \neq(\{1\})$ and $\mathrm{h}\left(D_{1}^{* x_{2}}\right) \neq(\{0\})$. Thus $C_{1}^{* x_{1}} \neq h^{-1}(\{1\})$ and $D_{1}^{* x_{2}} \neq h^{-1}(\{0\})$ where $\mathrm{h}=g \circ f: \mathrm{X} \rightarrow[0,1]$ is a continuous map. Hence by definition we have $(X, \tau)$ is a G-T $T_{6}$-space.

Theorem 3.4.4. If $\mathrm{f}:(\mathrm{X}, \tau) \rightarrow(\mathrm{Y}, \sigma)$ is one-one AO-map of a space $\mathrm{X}$ onto G- $T_{6}$ space $\mathrm{Y}$, then $\mathrm{X}$ is a $\mathrm{G}-\mathrm{T}_{6}$-space.

Proof: Let $C_{1}$ and $D_{1}$ be two disjoint sets in X. Since $\mathrm{f}$ is one-one and onto, there exists disjoint sets $C_{2}$ and $D_{2}$ of Y such that $f\left(C_{1}\right)=C_{2}$ and $f\left(D_{1}\right)=D_{2}$. Since $(\mathrm{Y}, \sigma)$ is G-T ${ }^{-}$ space, there exists a continuous map g: $\mathrm{Y} \rightarrow[0,1]$ such that $C_{2}^{* y_{1}} \neq g^{-1}(\{1\})$ and $D_{2}^{* y_{2}} \neq g^{-1}(\{0\})$. Since $\mathrm{f}$ is an AO-map, so that $C_{2}^{* y_{1}} \subseteq f\left(C_{1}^{* f^{-1}\left(y_{1}\right)}\right) \neq g^{-1}(\{1\})$ and $D_{2}^{* y_{2}} \subseteq f\left(D_{1}^{* f^{-1}\left(y_{2}\right)}\right) \neq g^{-1}(\{0\})$. This implies $\mathrm{f}\left(C_{1}^{* x_{1}}\right) \neq g^{-1}(\{1\})$ and $\mathrm{f}\left(D_{1}^{* x_{2}}\right) \neq$ $g^{-1}(\{0\})$. Now $\mathrm{g}\left(\mathrm{f}\left(C_{1}^{* x_{1}}\right)\right) \neq(\{1\})$ and $\mathrm{g}\left(\mathrm{f}\left(D_{1}^{* x_{2}}\right)\right) \neq(\{0\})$. This implies $\mathrm{h}\left(C_{1}^{* x_{1}}\right) \neq(\{1\})$ and $\mathrm{h}\left(D_{1}^{* x_{2}}\right) \neq(\{0\})$. Thus $C_{1}^{* x_{1}} \neq h^{-1}(\{1\})$ and $D_{1}^{* x_{2}} \neq h^{-1}(\{0\})$ where $\mathrm{h}=\mathrm{g} \circ f: \mathrm{X} \rightarrow$ $[0,1]$ is a continuous map. Hence by definition we have $(X, \tau)$ is a $\mathrm{G}-T_{6}$-space.

\section{5. $G^{*}-T_{3}$-space}

In this section we proved some theorems in connection with $I^{*}$-map, $I^{* *}$-map, A-map and AO-map for $G^{*}-T_{3}$-space. 
Theorem 3.5.1. If $\mathrm{f}:(\mathrm{X}, \tau) \rightarrow(\mathrm{Y}, \sigma)$ is one-one $I^{*}$-map of a $G^{*}-T_{3}$-space $\mathrm{X}$ onto a space $\mathrm{Y}$, then $\mathrm{Y}$ is a $G^{*}-T_{3}$-space.

Proof: Let $y_{1}$ and $C_{2}$ be a disjoint pair of Y. Since $\mathrm{f}$ is one-one and onto, there exists disjoint pair $x_{1}$ and $C_{1}$ of $\mathrm{X}$ such that $f\left(x_{1}\right)=y_{1}$ and $\mathrm{f}\left(C_{1}\right)=C_{2}$. Since $(\mathrm{X}, \tau)$ is $G^{*}-T_{3^{-}}$ space, there exists subset $\mathrm{A}$ of $\mathrm{X}$ such that $x_{1} \notin A^{* x_{2}}$ and $C_{1} \nsubseteq A^{* x_{1}}$, so that $f\left(x_{1}\right) \notin f\left(A^{* x_{2}}\right)=(f(A))^{* f\left(x_{2}\right)} \quad$ and $\quad f\left(C_{1}\right) \nsubseteq f\left(A^{* x_{1}}\right)=(f(A))^{* f\left(x_{1}\right)}$. Thus $y_{1} \notin(f(A))^{* f\left(x_{2}\right)=y_{2}}$ and $C_{2} \nsubseteq(f(A))^{* f\left(x_{1}\right)=y_{1}}$. Thus $\mathrm{Y}$ is a $G^{*}-T_{3}$-space.

Theorem 3.5.2. If $\mathrm{f}:(\mathrm{X}, \tau) \rightarrow(\mathrm{Y}, \sigma)$ is one-one $I^{* *}$-map of a space $\mathrm{X}$ onto $G^{*}-T_{3^{-}}$ space $\mathrm{Y}$, then $\mathrm{X}$ is a $G^{*}-T_{3}$-space.

Proof: Let $x_{1}$ and $C_{1}$ be a disjoint pairs of $\mathrm{X}$. Since $\mathrm{f}$ is one-one and onto, there exists disjoint pairs $y_{1}$ and $C_{2}$ of Y such that $f\left(x_{1}\right)=y_{1}$ and $f\left(C_{1}\right)=C_{2}$. Since ( Y, $\left.\sigma\right)$ is $G^{*}$ $T_{3}$-space, there exists subset $\mathrm{A}$ of $\mathrm{Y}$ such that $y_{1} \notin A^{* y_{2}}$ and $C_{2} \nsubseteq A^{* y_{1}}$, so that $f^{-1}\left(y_{1}\right) \notin f^{-1}\left(A^{* y_{2}}\right)=\left(f^{-1}(A)\right)^{* f^{-1}\left(\left(y_{2}\right)\right)} \quad$ and $\quad f^{-1}\left(C_{2}\right) \notin f^{-1}\left(A^{* y_{1}}\right) \quad=$

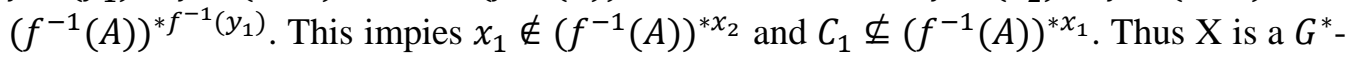
$T_{3}$-space.

Theorem 3.5.3. If $\mathrm{f}:(\mathrm{X}, \tau) \rightarrow(\mathrm{Y}, \sigma)$ is one-one A-map of an $G^{*}-T_{3}$-space $\mathrm{X}$ onto a space $\mathrm{Y}$, then $\mathrm{Y}$ is a $G^{*}-T_{3}$-space.

Proof: Let $y_{1}$ and $C_{2}$ be a disjoint pair of $\mathrm{Y}$. Since $\mathrm{f}$ is one-one and onto, there exists a disjoint pair $x_{1}$ and $C_{1}$ of X such that $f\left(x_{1}\right)=y_{1}$ and $f\left(C_{1}\right)=C_{2}$. Since $(X, \tau)$ is $G^{*}-T_{3^{-}}$ space, there exists subsets $\mathrm{A}$ of $\mathrm{X}$ such that $x_{1} \notin A^{* x_{2}}$ and $C_{1} \nsubseteq A^{* * x_{1}}$, so that $f\left(x_{1}\right) \notin f\left(A^{* x_{2}}\right) \subseteq B^{* f\left(x_{2}\right)}$ and $f\left(C_{1}\right) \nsubseteq f\left(A^{* x_{1}}\right) \subseteq B^{* f\left(x_{1}\right)}$. This implies $y_{1} \notin B^{* y_{2}}$ and $C_{2} \nsubseteq B^{* y_{1}}$. Thus $\mathrm{Y}$ is a $G^{*}-T_{3}$-space.

Theorem 3.5.4. If $\mathrm{f}:(\mathrm{X}, \tau) \rightarrow(\mathrm{Y}, \sigma)$ is one-one AO-map of a space $\mathrm{X}$ onto $G^{*}-T_{3^{-}}$ space $\mathrm{Y}$, then $\mathrm{X}$ is a $G^{*}-T_{3}$-space.

Proof: Let $x_{1}$ and $C_{1}$ be a disjoint pair of $\mathrm{X}$. Since $\mathrm{f}$ is one-one and onto, there exists a disjoint pair $y_{1}$ and $C_{2}$ of Y such that $f\left(x_{1}\right)=y_{1}$ and $f\left(C_{1}\right)=C_{2}$. Since $(\mathrm{Y}, \sigma)$ is $G^{*}-T_{3^{-}}$ space, there exists subset $\mathrm{B}$ of $\mathrm{Y}$ such that $y_{1} \notin B^{* y_{2}} \subseteq f\left(A^{* f^{-1}\left(y_{2}\right)}\right)$ and $C_{2} \nsubseteq B^{* y_{1}} \subseteq$ $f\left(A^{* f^{-1}\left(y_{1}\right)}\right)$, so that $f^{-1}\left(y_{1}\right) \notin f^{-1}\left(f\left(A^{* f^{-1}\left(y_{2}\right)}\right)\right)$ and $f^{-1}\left(C_{2}\right) \nsubseteq f^{-1}\left(f\left(A^{* f^{-1}\left(y_{1}\right)}\right)\right)$. This implies $x_{1} \notin A^{* x_{2}}$ and $C_{1} \nsubseteq A^{* x_{1}}$. Thus $\mathrm{X}$ is a $G^{*}$ - $T_{3}$-space.

\section{6. $G^{*}-T_{4}$-space}

In this section we proved some theorems in connection with $I^{*}$-map, $I^{* *}$-map, A-map and AO-map for $G^{*}-T_{4}$-space.

Theorem 3.6.1. If $\mathrm{f}:(\mathrm{X}, \tau) \rightarrow(\mathrm{Y}, \sigma)$ is one-one $I^{*}$-map of a $G^{*}-T_{4}$-space $\mathrm{X}$ onto a space $\mathrm{Y}$, then $\mathrm{Y}$ is a $G^{*}-T_{4}$-space.

Proof: Let $C_{2}$ and $D_{2}$ be two disjoint sets in Y. Since $\mathrm{f}$ is one-one and onto, there exists disjoint sets $C_{1}$ and $D_{1}$ of $\mathrm{X}$ such that $f\left(C_{1}\right)=C_{2}$ and $\mathrm{f}\left(D_{1}\right)=D_{2}$. Since $(\mathrm{X}, \tau)$ is $G^{*}-T_{4^{-}}$ space, there exists a subset $\mathrm{A}$ of $\mathrm{X}$ such that $C_{1} \nsubseteq A^{* x_{2}}$ and $D_{1} \nsubseteq A^{* x_{1}}$, so that $f\left(C_{1}\right) \nsubseteq f\left(A^{* x_{2}}\right)=(f(A))^{* f\left(x_{2}\right)} \quad$ and $\quad f\left(D_{1}\right) \nsubseteq f\left(A^{* x_{1}}\right)=(f(A))^{* f\left(x_{1}\right)}$. Thus 
Gem-Separation Axioms in Topological Space

$C_{2} \nsubseteq(f(A))^{* f\left(x_{2}\right)=y_{2}}$ and $D_{2} \nsubseteq(f(A))^{* f\left(x_{1}\right)=y_{1}}$. Thus $\mathrm{Y}$ is a $G^{*}-T_{4}$-space.

Theorem 3.6.2. If $\mathrm{f}:(\mathrm{X}, \tau) \rightarrow(\mathrm{Y}, \sigma)$ is one-one $I^{* *}$-map of a space $\mathrm{X}$ onto $G^{*}-T_{4}$ space $\mathrm{Y}$, then $\mathrm{X}$ is a $G^{*}-T_{4}$-space.

Proof: Let $C_{1}$ and $D_{1}$ be two disjoint sets in $\mathrm{X}$. Since $\mathrm{f}$ is one-one and onto, there exists disjoint sets $C_{2}$ and $D_{2}$ of Y such that $f\left(C_{1}\right)=C_{2}$ and $f\left(D_{1}\right)=D_{2}$. Since $(\mathrm{Y}, \sigma)$ is $G^{*}$ $T_{4}$-space, there exists a subset $\mathrm{A}$ of $\mathrm{Y}$ such that $C_{2} \nsubseteq A^{* y_{2}}$ and $D_{2} \nsubseteq A^{* y_{1}}$, so that $f^{-1}\left(C_{2}\right) \nsubseteq f^{-1}\left(A^{* y_{2}}\right) \quad=\quad\left(f^{-1}(A)\right)^{* f^{-1}\left(\left(y_{2}\right)\right)} \quad$ and $\quad f^{-1}\left(D_{2}\right) \nsubseteq f^{-1}\left(A^{* y_{1}}\right) \quad=$

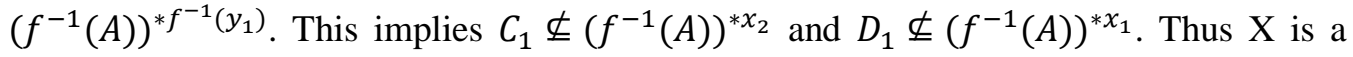
$G^{*}$ - $T_{4}$-space.

Theorem 3.6.3. If $\mathrm{f}:(\mathrm{X}, \tau) \rightarrow(\mathrm{Y}, \sigma)$ is one-one A-map of a $G^{*}-T_{4}$-space $\mathrm{X}$ onto a space $\mathrm{Y}$, then $\mathrm{Y}$ is a $G^{*}-T_{4}$-space.

Proof: Let $C_{2}$ and $D_{2}$ be two disjoint sets in Y. Since $\mathrm{f}$ is one-one and onto, there exists a disjoint sets $C_{1}$ and $D_{1}$ of $\mathrm{X}$ such that $f\left(C_{1}\right)=C_{2}$ and $f\left(D_{1}\right)=D_{2}$. Since $(\mathrm{X}, \tau)$ is $G^{*}-T_{4}$ space, there exists a subset $\mathrm{A}$ of $\mathrm{X}$ such that $C_{1} \nsubseteq A^{* x_{2}}$ and $D_{1} \nsubseteq A^{* x_{1}}$, so that $f\left(C_{1}\right) \nsubseteq f\left(A^{* x_{2}}\right) \subseteq B^{* f\left(x_{2}\right)}$ and $f\left(D_{1}\right) \nsubseteq f\left(A^{* x_{1}}\right) \subseteq B^{* f\left(x_{1}\right)}$. This implies $C_{2} \nsubseteq B^{* y_{2}}$ and $D_{2} \nsubseteq B^{* y_{1}}$. Thus $\mathrm{Y}$ is a $G^{*}$-T $T_{4}$-space.

Theorem 3.6.4. If $\mathrm{f}:(\mathrm{X}, \tau) \rightarrow(\mathrm{Y}, \sigma)$ is one-one AO-map of a space $\mathrm{X}$ onto $G^{*}-T_{4}$ space $\mathrm{Y}$, then $\mathrm{X}$ is a $G^{*}-T_{4}$-space.

Proof: Let $C_{1}$ and $D_{1}$ be two disjoint sets in $\mathrm{X}$. Since $\mathrm{f}$ is one-one and onto, there exists a disjoint sets $C_{2}$ and $D_{2}$ of Y such that $f\left(C_{1}\right)=C_{2}$ and $f\left(D_{1}\right)=D_{2}$. Since ( $\left.\mathrm{Y}, \sigma\right)$ is $G^{*}$ $T_{4}$-space, there exists subsets $\mathrm{B}$ of $\mathrm{Y}$ such that $C_{2} \nsubseteq B^{* y_{2}} \subseteq f\left(A^{* f^{-1}\left(y_{2}\right)}\right)$ and $D_{2} \nsubseteq B^{* y_{1}} \subseteq f\left(A^{* f^{-1}\left(y_{1}\right)}\right)$, so that $f^{-1}\left(C_{2}\right) \nsubseteq f^{-1}\left(f\left(A^{* f^{-1}\left(y_{2}\right)}\right)\right)$ and $f^{-1}\left(D_{2}\right) \nsubseteq f^{-1}\left(f\left(A^{* f^{-1}\left(y_{1}\right)}\right)\right)$. This implies $C_{1} \nsubseteq A^{* x_{2}}$ and $D_{1} \nsubseteq A^{* x_{1}}$. Thus $\mathrm{X}$ is a $G^{*}$ $T_{4}$-space.

\section{7. $G^{*}-T_{5}$-space}

In this section we proved some theorems in connection with $I^{*}$-map, $I^{* *}$-map, A-map and AO-map for $G^{*}-T_{5}$-space.

Theorem 3.7.1. If $\mathrm{f}:(\mathrm{X}, \tau) \rightarrow(\mathrm{Y}, \sigma)$ is one-one $I^{*}$-map of a $G^{*}-T_{5}$-space $\mathrm{X}$ onto a space $\mathrm{Y}$, then $\mathrm{Y}$ is a $G^{*}-T_{5}$-space.

Proof: Let $C_{2}$ and $D_{2}$ be separated sets in Y. Since $\mathrm{f}$ is one-one and onto, there exists separated sets $C_{1}$ and $D_{1}$ of $\mathrm{X}$ such that $f\left(C_{1}\right)=C_{2}$ and $\mathrm{f}\left(D_{1}\right)=D_{2}$. Since $(\mathrm{X}, \tau)$ is $G^{*}$ $T_{5}$-space, there exists subset $\mathrm{A}$ of $\mathrm{X}$ such that $C_{1} \nsubseteq A^{* x_{2}}$ and $D_{1} \nsubseteq A^{* x_{1}}$, so that $f\left(C_{1}\right) \nsubseteq f\left(A^{* x_{2}}\right)=(f(A))^{* f\left(x_{2}\right)} \quad$ and $\quad f\left(D_{1}\right) \nsubseteq f\left(A^{* x_{1}}\right)=(f(A))^{* f\left(x_{1}\right)}$. Thus $C_{2} \nsubseteq(f(A))^{* f\left(x_{2}\right)=y_{2}}$ and $D_{2} \nsubseteq(f(A))^{* f\left(x_{1}\right)=y_{1}}$. Thus $\mathrm{Y}$ is a $G^{*}-T_{5}$-space.

Theorem 3.7.2. If $\mathrm{f}:(\mathrm{X}, \tau) \rightarrow(\mathrm{Y}, \sigma)$ is one-one $I^{* *}$-map of a space $\mathrm{X}$ onto $G^{*}-T_{5^{-}}$ space $\mathrm{Y}$, then $\mathrm{X}$ is a $G^{*}-T_{5}$-space.

Proof: Let $C_{1}$ and $D_{1}$ be separated sets in $\mathrm{X}$. Since $\mathrm{f}$ is one-one and onto, there exists separated sets $C_{2}$ and $D_{2}$ of Y such that $f\left(C_{1}\right)=C_{2}$ and $f\left(D_{1}\right)=D_{2}$. Since (Y, $\sigma$ ) is $G^{*}$ $T_{5}$-space, there exists subset $\mathrm{A}$ of $\mathrm{Y}$ such that $C_{2} \nsubseteq A^{* y_{2}}$ and $D_{2} \nsubseteq A^{* y_{1}}$, so that 
R. Rathinam and C. Elango

$f^{-1}\left(C_{2}\right) \nsubseteq f^{-1}\left(A^{* y_{2}}\right) \quad=\quad\left(f^{-1}(A)\right)^{* f^{-1}\left(\left(y_{2}\right)\right)} \quad$ and $\quad f^{-1}\left(D_{2}\right) \nsubseteq f^{-1}\left(A^{* y_{1}}\right) \quad=$

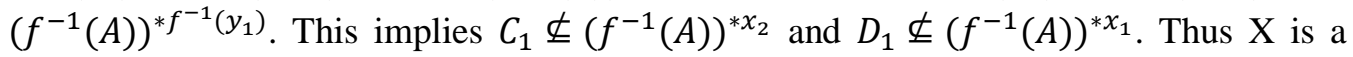
$G^{*}-T_{5}$-space.

Theorem 3.7.3. If $\mathrm{f}:(\mathrm{X}, \tau) \rightarrow(\mathrm{Y}, \sigma)$ is one-one A-map of an $G^{*}-T_{5}$-space $\mathrm{X}$ onto a space $\mathrm{Y}$, then $\mathrm{Y}$ is a $G^{*}-T_{5}$-space.

Proof: Let $C_{2}$ and $D_{2}$ be separated sets in Y. Since $\mathrm{f}$ is one-one and onto, there exists separated sets $C_{1}$ and $D_{1}$ of X such that $f\left(C_{1}\right)=C_{2}$ and $f\left(D_{1}\right)=D_{2}$. Since (X, $\left.\tau\right)$ is $G^{*}$ $T_{5}$-space, there exists subset $\mathrm{A}$ of $\mathrm{X}$ such that $C_{1} \nsubseteq A^{* x_{2}}$ and $D_{1} \nsubseteq A^{* x_{1}}$, so that $f\left(C_{1}\right) \nsubseteq f\left(A^{* x_{2}}\right) \subseteq B^{* f\left(x_{2}\right)}$ and $f\left(D_{1}\right) \nsubseteq f\left(A^{* x_{1}}\right) \subseteq B^{* f\left(x_{1}\right)}$. This implies $C_{2} \nsubseteq B^{* y_{2}}$ and $D_{2} \nsubseteq B^{* y_{1}}$. Thus $\mathrm{Y}$ is a $G^{*}-T_{5}$-space.

Theorem 3.7.4. If $\mathrm{f}:(\mathrm{X}, \tau) \rightarrow(\mathrm{Y}, \sigma)$ is one-one AO-map of a space $\mathrm{X}$ onto $G^{*}-T_{5^{-}}$ space $\mathrm{Y}$, then $\mathrm{X}$ is a $G^{*}-T_{5}$-space.

Proof: Let $C_{1}$ and $D_{1}$ be separated sets in $\mathrm{X}$. Since $\mathrm{f}$ is one-one and onto, there exists separated sets $C_{2}$ and $D_{2}$ of Y such that $f\left(C_{1}\right)=C_{2}$ and $f\left(D_{1}\right)=D_{2}$. Since $(\mathrm{Y}, \sigma)$ is $G^{*}$ $T_{5}$-space, there exists subset $\mathrm{B}$ of $\mathrm{Y}$ such that $C_{2} \nsubseteq B^{* y_{2}} \subseteq f\left(A^{* f^{-1}\left(y_{2}\right)}\right)$ and $D_{2} \nsubseteq B^{* y_{1}} \subseteq f\left(A^{* f^{-1}\left(y_{1}\right)}\right)$, so that $f^{-1}\left(C_{2}\right) \nsubseteq f^{-1}\left(f\left(A^{* f^{-1}\left(y_{2}\right)}\right)\right)$ and

$f^{-1}\left(D_{2}\right) \nsubseteq f^{-1}\left(f\left(A^{* f^{-1}\left(y_{1}\right)}\right)\right)$. This implies $C_{1} \nsubseteq A^{* x_{2}}$ and $D_{1} \nsubseteq A^{* x_{1}}$. Thus $\mathrm{X}$ is a $G^{*}$ $T_{5}$-space.

\section{8. $G^{*}-T_{6}$-space}

In this section we proved some theorems in connection with $I^{*}$-map, $I^{* *}$-map, A-map and AO-map for $G^{*}-T_{6}$-space.

Theorem 3.8.1. If $\mathrm{f}:(\mathrm{X}, \tau) \rightarrow(\mathrm{Y}, \sigma)$ is one-one $I^{*}$-map of a space $\mathrm{X}$ onto $G^{*}$ - $T_{6}$-space $\mathrm{Y}$, then $\mathrm{X}$ is a $G^{*}-T_{6}$-space.

Proof: Let $C_{1}$ and $D_{1}$ be two disjoint sets in X. Since $\mathrm{f}$ is one-one and onto, there exists disjoint sets $C_{2}$ and $D_{2}$ of Y such that $f\left(C_{1}\right)=C_{2}$ and $f\left(D_{1}\right)=D_{2}$. Since $\mathrm{f}$ is an $I^{*}$-map, so that $\mathrm{f}\left(C_{1}^{* x_{1}}\right)=\left(f\left(C_{1}\right)\right)^{* f\left(x_{1}\right)}=C_{2}^{* y_{1}}$ and $\mathrm{f}\left(D_{1}^{* x_{2}}\right)=\left(f\left(D_{1}\right)\right)^{* f\left(x_{2}\right)}=D_{2}^{* y_{2}}$ Since $(\mathrm{Y}, \sigma)$ is $G^{*}-T_{6}$-space, there exists a continuous map $\mathrm{g}: \mathrm{Y} \rightarrow[0,1]$ such that $C_{2}^{* y_{1}} \neq g^{-1}(\{1\})$ and $D_{2}^{* y_{2}}=g^{-1}(\{1\})$. This implies $\mathrm{f}\left(C_{1}^{* x_{1}}\right) \neq g^{-1}(\{1\})$ and $\mathrm{f}\left(D_{1}^{* x_{2}}\right)=g^{-1}(\{1\})$. Now $\mathrm{g}\left(\mathrm{f}\left(C_{1}^{* x_{1}}\right)\right) \neq(\{1\})$ and $\mathrm{g}\left(\mathrm{f}\left(D_{1}^{* x_{2}}\right)\right)=(\{1\})$. This implies $\mathrm{h}\left(C_{1}^{* x_{1}}\right) \neq(\{1\})$ and $\mathrm{h}\left(D_{1}^{* x_{2}}\right)=$ (\{1\}). Thus $C_{1}^{* x_{1}} \neq h^{-1}(\{1\})$ and $D_{1}^{* x_{2}}=h^{-1}(\{1\})$ where $\mathrm{h}=\mathrm{g} \circ f: \mathrm{X} \rightarrow[0,1]$ is a continuous map. Hence by definition we have $(X, \tau)$ is a $G^{*}-T_{6}$-space.

Theorem 3.8.2. If $\mathrm{f}:(\mathrm{X}, \tau) \rightarrow(\mathrm{Y}, \sigma)$ is one-one $I^{* *}$-map of a space $\mathrm{X}$ onto $G^{*}-T_{6}$ space $\mathrm{Y}$, then $\mathrm{X}$ is a $G^{*}-T_{6}$-space.

Proof: Let $C_{1}$ and $D_{1}$ be two disjoint sets in $\mathrm{X}$. Since $\mathrm{f}$ is one-one and onto, there exists disjoint sets $C_{2}$ and $D_{2}$ of $\mathrm{Y}$ such that $f\left(C_{1}\right)=C_{2}$ and $f\left(D_{1}\right)=D_{2}$. Since $(\mathrm{Y}, \sigma)$ is $G^{*}-T_{6^{-}}$ space, there exists a continuous map $\mathrm{g}: \mathrm{Y} \rightarrow[0,1]$ such that $C_{2}^{* y_{1}} \neq g^{-1}(\{1\})$ and $D_{2}^{* y_{2}}$ $=g^{-1}(\{1\})$. So that $f^{-1}\left(C_{2}^{* y_{1}}\right) \neq f^{-1}\left(g^{-1}(\{1\})\right)$ and $f^{-1}\left(D_{2}^{* y_{2}}\right)=f^{-1}\left(g^{-1}(\{1\})\right)$. This implies $f^{-1}\left(C_{2}^{* y_{1}}\right) \neq h^{-1}(\{1\})$ and $f^{-1}\left(D_{2}^{* y_{2}}\right)=h^{-1}(\{1\})$. Since $\mathrm{f}$ is an $I^{* *}$-map, we have $\left(f^{-1}\left(C_{2}\right)\right)^{* f^{-1}\left(y_{1}\right)} \neq h^{-1}(\{1\})$ and $\left(f^{-1}\left(D_{2}\right)\right)^{* f^{-1}\left(y_{2}\right)}=h^{-1}(\{1\})$. This implies 
Gem-Separation Axioms in Topological Space

$C_{1}^{* x_{1}} \neq h^{-1}(\{1\})$ and $D_{1}^{* x_{2}}=h^{-1}(\{1\})$ where $\mathrm{h}=\mathrm{g} \circ f: \mathrm{X} \rightarrow[0,1]$ is a continuous map. Thus by definition we have $(\mathrm{X}, \tau)$ is a $G^{*}-T_{6}$-space.

Theorem 3.8.3. If $\mathrm{f}:(\mathrm{X}, \tau) \rightarrow(\mathrm{Y}, \sigma)$ is one-one A-map of a space $\mathrm{X}$ onto $G^{*}-T_{6}$-space $\mathrm{Y}$, then $\mathrm{X}$ is a $G^{*}-T_{6}$-space.

Proof: Let $C_{1}$ and $D_{1}$ be two disjoint sets in $\mathrm{X}$. Since $\mathrm{f}$ is one-one and onto, there exists disjoint sets $C_{2}$ and $D_{2}$ of Y such that $f\left(C_{1}\right)=C_{2}$ and $f\left(D_{1}\right)=D_{2}$. Since $\mathrm{f}$ is an A-map, so that $\mathrm{f}\left(C_{1}^{* x_{1}}\right) \subseteq C_{2}^{* f\left(x_{1}\right)}=C_{2}^{* y_{1}}$ and $\mathrm{f}\left(D_{1}^{* x_{2}}\right) \subseteq D_{2}^{* f\left(x_{2}\right)}=D_{2}^{* y_{2}}$ Since $(\mathrm{Y}, \sigma)$ is $G^{*}-T_{6}$ space, there exists a continuous map $\mathrm{g}: \mathrm{Y} \rightarrow[0,1]$ such that $C_{2}^{* y_{1}} \neq g^{-1}(\{1\})$ and $D_{2}^{* y_{2}}$ $=g^{-1}(\{1\})$. This implies $\mathrm{f}\left(C_{1}^{* x_{1}}\right) \subseteq C_{2}^{* y_{1}} \neq g^{-1}(\{1\})$ and $\mathrm{f}\left(D_{1}^{* x_{2}}\right) \subseteq D_{2}^{* y_{2}}=g^{-1}(\{1\})$. This implies $\mathrm{f}\left(C_{1}^{* x_{1}}\right) \neq g^{-1}(\{1\})$ and $\mathrm{f}\left(D_{1}^{* x_{2}}\right)=g^{-1}(\{1\})$. Now $\mathrm{g}\left(\mathrm{f}\left(C_{1}^{* x_{1}}\right)\right) \neq(\{1\})$ and $\mathrm{g}\left(\mathrm{f}\left(D_{1}^{* x_{2}}\right)\right)=(\{1\})$. This implies $\mathrm{h}\left(C_{1}^{* x_{1}}\right) \neq(\{1\})$ and $\mathrm{h}\left(D_{1}^{* x_{2}}\right)=(\{1\})$. Thus $C_{1}^{* x_{1}} \nsubseteq h^{-1}(\{1\})$ and $D_{1}^{* x_{2}} \subseteq h^{-1}(\{1\})$ where $\mathrm{h}=\mathrm{g} \circ f: \mathrm{X} \rightarrow[0,1]$ is a continuous map. Hence by definition we have (X, $\tau$ ) is a $G^{*}-T_{6}$-space.

Theorem 3.8.4. If $\mathrm{f}:(\mathrm{X}, \tau) \rightarrow(\mathrm{Y}, \sigma)$ is one-one AO-map of a space $\mathrm{X}$ onto $G^{*}-T_{6}$ space $\mathrm{Y}$, then $\mathrm{X}$ is a $G^{*}-T_{6}$-space.

Proof: Let $C_{1}$ and $D_{1}$ be two disjoint sets in $\mathrm{X}$. Since $\mathrm{f}$ is one-one and onto, there exists disjoint sets $C_{2}$ and $D_{2}$ of Y such that $f\left(C_{1}\right)=C_{2}$ and $f\left(D_{1}\right)=D_{2}$. Since $(\mathrm{Y}, \sigma)$ is $G^{*}-T_{6}$ space, there exists a continuous map $\mathrm{g}: \mathrm{Y} \rightarrow[0,1]$ such that $C_{2}^{* y_{1}} \neq g^{-1}(\{1\})$ and $D_{2}^{* y_{2}}$ $=g^{-1}(\{1\})$. Since $\mathrm{f}$ is an AO-map, so that $C_{2}^{* y_{1}} \subseteq f\left(C_{1}^{* f^{-1}\left(y_{1}\right)}\right) \neq g^{-1}(\{1\})$ and $D_{2}^{* y_{2}} \subseteq$ $f\left(D_{1}^{* f^{-1}\left(y_{2}\right)}\right)=g^{-1}(\{1\})$. This implies $\mathrm{f}\left(C_{1}^{* x_{1}}\right) \neq g^{-1}(\{1\})$ and $\mathrm{f}\left(D_{1}^{* x_{2}}\right)=g^{-1}(\{1\})$. Now $\mathrm{g}\left(\mathrm{f}\left(C_{1}^{* x_{1}}\right)\right) \neq(\{1\})$ and $\mathrm{g}\left(\mathrm{f}\left(D_{1}^{* x_{2}}\right)\right)=(\{1\})$. This implies $\mathrm{h}\left(C_{1}^{* x_{1}}\right) \neq(\{1\})$ and $\mathrm{h}\left(D_{1}^{* x_{2}}\right)=$ $(\{1\})$. Thus $C_{1}^{* x_{1}} \neq h^{-1}(\{1\})$ and $D_{1}^{* x_{2}}=h^{-1}(\{1\})$ where $\mathrm{h}=\mathrm{g} \circ f: \mathrm{X} \rightarrow[0,1]$ is a continuous map. Hence by definition we have $(X, \tau)$ is a $G^{*}-T_{6}$-space.

\section{Conclusion}

In this article, we studied some basic concepts and relations involving Gem-separation axioms. We also rename $I^{*}-T_{0}$-space, $I^{*}$ - $T_{1}$-space, $I^{*}-T_{2}$-space by Gem-Kolmogorov space(G-T $T_{0}$-space), Gem-accessible space or Gem-Frechlet space(G-T $T_{1}$-space) and GemHausdorff space(G-T $T_{2}$-space) and $I^{* *}-T_{i}$-spaces by $G^{*}-T_{i}$-spaces. In future the concepts used in nano-topology can be adopted to prove that Gem-set in nano topological space.

\section{REFERENCES}

1. A.Gupta and R.Kaur, Compact spaces with respect to an Ideal, Int. Journal of Pure and Applied Math., 3(92) (2014) 443-448.

2. D.Jankovic and T.R.Hamlett, Compactible extensions of Ideals, Bollettino della U.M.I, 6 (7) (1992) 453-465.

3. D.Jankovic and T.R.Hamlett, Compactness with respect to an Ideal, Bollettino della U.M.I, 7 (1990) 849-861.

4. D.Jankovic and T.R.Hamlett, New topologies from old via ideals, The Amer. Math. Monthly, 97 (1990) 295-310.

5. F.G.Arenas and J.Dontchev and M.L.Puertas, Idealization of some weak separation axiom, Acta Math. Hungarica, 2 (89) (2000) 47-53. 
R. Rathinam and C. Elango

6. John L.Kelley, General Topology, First Edition, (1955).

7. J.R.Munkres, Topology, Second Edition, (2000).

8. K.Kuratowski, Topologies I, Academic press, New York, (1966).

9. L.A.AL-Swidi and Ahmed B.AL.Nafee, New Separation Axioms Using the Idea of "Gem-Set" in topological space, Mathematical Theory and Modeling, 3 (3) (2013) 60-66.

10. L.A.AL-.Swidi and Dheargham A.AL-Sada, Turning point of proper ideal, JST Journal. Archive Des Science, 7 (65) (2012) 213-220.

11. L.A.AL-.Swidi and M.A.AL-Ethary, Compactness with gem-set, Int. Journal of Math. Analysis, 23 (8) (2014) 1105-1117.

12. L.A.AL-.Swidi and M.A.AL-Ethary, New Function with "Gem-Set" in Topological space, Int. Journal of Engg. Research and Technology, 2(3) (2014) 2324-2327.

13. L.A.AL-.Swidi and M.S.AL-Rubaye, New classes of separation axiom via special case of local function, Int. Journal of Math. Analysis, 23 (8) (2014) 1119-1131.

14. L.A.AL-.Swidi and M.S.AL-Rubaye, On separation axioms with respect to gem-set, Int. Journal of Engg Research and Technology, 2 (3) (2014) 2789-2792.

15. R.Manoharan and P.Thangavelu, Some New Sets and Topologies in Ideal Topological Spaces, Chinese Journal of Mathematics (2013).

16. R.Vaidyanathaseamy, Set Topology, Chelsea Publishing CO., New york (1960).

17. T.R.Hamlett and D.Jankovic, Ideals in topological spaces and the set operator, Bollettino dell U.M.I., 7 (1990) 863-874.

18. T.R.Hamlett and D.Jankovic, Ideals in general topology, General Topology and Applications, (1988) 115-125. 